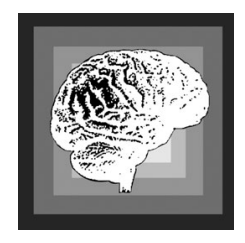

\title{
Letters to the Editor on Norwegian psychiatry
}

\section{Development of 'psychiatry' and the mental health services in Norway}

Einar Kringlen's 2004 article 'A history of Norwegian psychiatry', published in this journal, needs some corrections and some additional comments. The author is Emeritus Professor of Psychiatry at the University of Oslo, Norway. Even if his description and evaluation of 'psychiatry' in Norway from the eighteenth century to the present day is said to be a personal and subjective account, it should still have been clearly written, without contradictions, and the details should have been correct. This is what is expected from articles published in History of Psychiatry. Kringlen's paper does not comply with these requirements. It is unclear what it is about, and there are inconsistencies and errors. Altogether, it seems to be a skimped work, as the following examples show.

On page 259, Norwegian 'psychiatry' is described in this way: 'Until the end of World War II, psychiatry in ... Norway ... was mainly a hospital psychiatry, strongly influenced by the German tradition.' But on page 266 we read: 'After World War II Norwegian psychiatry was basically a hospital psychiatry, strongly influenced by German psychiatry ...' (my italics in both quotes). Does this mean that it has always been 'a hospital psychiatry', and why mention World War II at all? The fact, however, is that up to 1950 there were about as many patients outside the hospitals, especially in private care, as there were inside these institutions. When the number of patients in the mental hospitals peaked about 1965 at 8515 in-patients, the situation was about the same: 4850 patients in private care and 3179 in other institutions (Hagen, 2001: 29). Therefore, to characterize Norwegian 'psychiatry' as hospital based before and after World War II is not very appropriate.

On page 264 Kringlen states: 'Research activity in psychiatry was low before the war', and one sentence further on: 'However, several important pieces of research appeared in the 1930s.' Is 'several pieces' meant as an illustration of 'low activity'?

Kringlen does not refer to the latest and comprehensive thesis about the history of 'psychiatry' in Norway (Skålevåg, 2003), but calls the author 'Skålevig' when citing two of his earlier papers. 


\section{What does 'psychiatry' mean in the article?}

The article deals with different issues, and it is hard to tell what it is actually about: is it a history of the asylums or psychiatric institutions in Norway, about a medical speciality, psychiatry, about the mental health services, about the 'great psychiatrists', about psychiatric epidemiology? The title does not reveal the content, and the author does not define or discuss what is meant by 'psychiatry' in this context. Generally the concepts or the words used in the article lack any definition. The precision in thinking expressed in this piece of writing is poor, and most of the topics mentioned above are dealt with in only a superficial way.

The presentation is also characterized by its uncritical view of colleagues. Kringlen does not mention, for instance, Professor Ødegård's active promotion and responsibility for the extensive use of lobotomy in Norway, but instead concentrates on Ødegård's contribution to psychiatric epidemiology. In the reference list there are 13 papers by Ødegård, none of them referring to his achievements in the field of lobotomy (see Tranøy and Blomberg, 2005). The extensive use of this treatment procedure for many years at the mental hospitals in 1940s and 50s is more relevant for the history of 'psychiatry' in Norway than epidemiological studies reporting that emigrants to Minnesota had a higher rate of first admissions of psychosis - studies which Kringlen emphasizes, together with detailed discussions of results from other epidemiological and treatment studies. Sometimes one gets the impression that the paper is dealing with some aspects of the history of psychiatric epidemiology.

\section{The important men in the history of Norwegian psychiatry}

Ødegård is not the only medical doctor or psychiatrist who is depicted in a pleasing and uncritical manner by Kringlen. This way of writing a history of psychiatry reminds me of the tradition of telling the history of a country by concentrating on the kings (and queens). Many of the professors of psychiatry and the directors of the mental hospitals are carefully described, for instance, the following. Fredrik Holst: 'Influenced by the humanitarian ideas ... tried to improve the social conditions ...' . Herman Major: 'could take credit for both the new 1848 law on mental health and the building of Gaustad Asylum'; he also 'argued strongly for reforms, putting forward both human and economic considerations'. Kringlen mentions the first Professor of Psychiatry, Ragnar Vogt, 'with his liberal and tolerant attitude'. In addition, Professor Johan Scharffenberg 'played a decisive role in public life with his struggle for social reforms', and was 'a brave anti-Nazi'. Ørnulv Ødegård, Professor of Psychiatry at Oslo University and Director at Gaustad Asylum, was 'an impressive research psychiatrist of international standing'. Others included are: '[T] he charismatic Gordon Johnsen', the founder of Modum Bads Nervesanatorium; 'the prolific independent writer Trygve Braatøy' (a psychiatrist); Nils Retterstøl, Professor at 
Gaustad Hospital, 'a hardworking writer'; and Odd Lingiærde, Professor of Psychiatry, whose 'textbook of psychopharmacology has appeared in several editions'.

This flattery of men (all the many individuals mentioned in Kringlen's paper are men) in a scientific paper may pass as a friendly gesture to colleagues. But surely it was these people - the heads of the institutions, those in charge of the day-to-day running, and the leaders of the top administration - who were responsible for the misery in the mental health services, also described by Kringlen.

\section{'Scientific treatment'}

On the one hand, Kringlen does not have one word of criticism for his colleagues in leading positions. On the other hand, he does not hold back in criticizing the system or the situation at the institutions and in the mental health services in general. However, he makes no critical comments on the treatment procedures, for instance, lobotomy or '[i]nsulin-coma treatment ... applied to schizophrenia' (p. 266).

Before medical doctors became responsible for the mental health services and undertook treatment, "“[s]cientific treatment" was unknown', according to Kringlen (p. 261). Does it mean that treatment since then has been based on scientific knowledge? - for example, when '[v]arious herbs and extracts were ... applied in different conditions' (p. 261), and when medical doctors (for instance, Ludvig Dahl at Gaustad Asylum) emphasized masturbation as a causal factor for mental insanity? To declare insanity an organic disease and order mainly psychosocial therapy, influenced by moral treatment (p. 262) does not seem to be very scientific either. The examples mentioned do not represent any scientific progress compared with the period before the medical profession took responsibility for explanation and treatment.

One of the new somatic treatment methods introduced in the hospitals in the 1930s by the leading psychiatrists, electroconvulsive (electroshock) therapy without modern anaesthesia, is described by Kringlen as 'uncomfortable' for the patients (p. 266). This is certainly an understatement, since 'broken bones during epileptic attacks were not uncommon' (p. 267). Nobody is held by Kringlen to be responsible for the maltreatment, even when the indications were extended so that 'half the in-patients at the university department at Vinderen were treated with electroconvulsive therapy' (p. 267). These examples of 'scientific treatment' and progress in psychiatry do not reassure those who doubt the scientific progress in medicine and its relevance for mentally disordered people.

\section{Severe shortcomings in the mental health services}

In the post-war years, severe criticism of the mental health services increased. 
Kringlen does mention that 'For many years, overcrowded mental hospitals had been a recurrent problem' (p. 266), but he does not analyse the situation. $\mathrm{He}$ also mentions that 'newspapers frequently criticized living conditions of psychiatric patients' (p. 268), especially at the mental hospitals. But Kringlen does not explain who was responsible for these miseries which lasted for decades.

A recent Government White Paper (Sosial- og helsedepartementet, 1997) stated clearly that the mental health services in Norway had severe shortcomings. The facilities were imperfect and insufficient, the thresholds for getting treatment were too high, the after-care was lacking and the cooperation between the primary care and the specialized mental health services was inadequate. Productivity and efficiency had to be improved, and the use of compulsory admission and force should be reduced.

\section{Compulsory admission and coercive methods}

Kringlen pays little attention to another hallmark of 'psychiatry' in Norway, but he mentions it in remarkable manner: 'When the new state asylums were built, a non-restraint system was introduced. However, coercive methods were never completely abolished' (p. 262). It is a huge understatement to say that they were not 'completely abolished' after the medical profession opened the asylums. The truth is that Norway has a long tradition of extensive use of compulsory admissions and has been a world leader in use of this kind of force in 'psychiatry'. About $40 \%$ of in-patient admissions are still the result of compulsory admission (Hatling, Bjørngaard and Husby, 2003); this rate is higher than in most other countries. In Denmark, for instance, it is about $10 \%$ (Hatling, Krogen and Ulleberg, 2002). A substantial proportion of Norwegian compulsory admissions are based on criteria that would not permit compulsory admission in other countries. This situation has been accepted for many years by the profession which decides about compulsory admissions, the psychiatrists. This interesting story about 'psychiatry' in Norway is hardly mentioned by Kringlen, except for the statement quoted above.

\section{Name-dropping is not enough}

To sum up, here is Kringlen's own description of the psychiatric institutions about 100 years after the medical profession had taken command and responsibility for the care of the patients:

Patients in the mental hospitals experienced a sad life in the post-war period. ... the asylum often resembled a prison more than a hospital. Many patients stayed there for life, and often there were 10-20 patients in one room, with practically no personal belongings. Some were given occupational therapy, but many were without any meaningful stimulation. (p. 267) 
We have to ask: who is, at least partly, responsible for all the miseries in the mental health services, if not those in charge, the heads of the institutions and the leading psychiatrists? Writing history also includes being critical towards powerful individuals, even if they are or have been professional colleagues. A history of the mental health services in Norway should analyse the contribution from the profession in charge since 1850: the psychiatrists. Name-dropping is not sufficient, and this part of the history of 'psychiatry' remains to be written.

Kringlen's apologetic storytelling expresses values and attitudes, and it is not an attempt to make an objective or neutral presentation of a science, a psychiatric practice or a public service. It makes discussions and conflict of opinion possible. My comments so far have concentrated on his propensity not only to accept, but also to praise everything the psychiatrists have done in the field, and never to blame them for any shortcomings; also, he hardly mentions other mental health service professions, which outnumber psychiatrists by thousands in the mental health services.

\section{Some facts}

Finally, I take issue with some 'facts' given by Kringlen in his paper. In each example, I will quote his words, and then provide facts and statistics from other publications.

Page 279: 'During the last decades we have also witnessed an increasing frequency of common depression, alcohol and substance abuse, anti-social behaviour and suicide in the younger generation.' The incidence for depression, abuse and anti-social behaviour is difficult to establish without discussing the indications and the instruments for measurement. For suicide in the younger generation, the figures from Statistics Norway do not support Kringlen's allegation: the number of suicides (below 30 years) has decreased since the end of the 1980s, from 161 in $1986-90$ to 115 in $2002 .{ }^{1}$

Page 279: 'Today there are more than 1000 psychiatrists and more than 1500 psychologists working in mental health [sic].' In 2003 the figure for psychologists working in the mental health services (primary care and specialist services) was about 2700 man-years, i.e., 60 man-years per 100,000 inhabitants. Comparable figures for psychiatrists are 713 , i.e., 15 per 100,000 inhabitants. ${ }^{2}$ Today there are more psychologists than psychiatrists employed in the mental health services in the adult services as well as in the services for children and adolescents.

Page 280 (in the summary): '[T] here has been a reduction in mental hospital beds since the mid-1960s, and private care of chronic patients has declined radically. However, at the same time there has been an increase in nursing homes. Thus, the total reduction of institutional beds has been moderate.' The average number of patients in these beds has dropped from 12,448 in 1970 (Hagen, 2001: 29) to 4,585 at the end of $2003 .^{3}$ That is a 
reduction of 7,863 or $63 \%$ beds/patients in the psychiatric institutions since 1970. If this is moderate, what is large?

In conclusion, Kringlen's article about psychiatry in Norway leaves the reader wondering about the real history.

\author{
ARNULF KOLSTAD \\ Department of Psychology \\ Norwegian University of Science and Technology (NTNU) \\ 7491 Trondheim, Norway \\ Email: arnulf.kolstad@svt.ntnu.no
}

\title{
Notes
}

1. Statistics Norway (Statistisk sentralbyrå): http://www.ssb.no/emner/03/01/10/dodsarsak/tab2004-02-27-08.html

2. Figures for 2003 are calculated from the most recent statistics given by Statistics Norway: http:www.ssb.no/English; and by SAMDATA/psykisk helsevern, 2003: http://www. samdata.sintef.no/?p=psykisk_helsevern/psykisk_helsevern.htm (also published in hard copy).

3. Figures for 2003 are given in a personal communication from SINTEF/Helse (data not yet published).

\section{References}

Hagen, H. (2001) Pasienter $i$ psykisk helsevern for voksne [Patients in the mental health services for adults] (Trondheim: SINTEF Unimed Helsetjenesteforskning, Report 5/01).

Hatling, T., Bjørngaard, J. H. and Husby, T. (2003) Tvangsinnleggelser [Compulsory admissions]. In H. Hagen (ed.), Opptrappingsplanen for psykisk helse - status etter fire àr [National Mental Health Programme - status after four years] (Trondheim: SINTEF Unimed Helsetjenesteforskning, Report 3/03).

Hatling, T., Krogen, T. and Ulleberg, P. (2002) Compulsory admissions to psychiatric hospitals in Norway - international comparisons and regional variations. Fournal of Mental Health, 11(6), 623-34.

Kringlen, E. (2004) A history of Norwegian psychiatry. History of Psychiatry, 15(3), 259-83.

Skålevåg, S. A. (2003) Fra normalitetens historie. Sinnsykdom 1870-1920 [From the history of normality. Mental illness 1870-1920] (Bergen: Rokkansenteret).

Sosial- og helsedepartementet (1997) St. Meld. 25 (1996-97): Apenhet og helhet. Om psykiske lidelser og tjenestetilbudene [Openness and comprehensiveness. Psychiatric disorders and the mental health services] (Oslo: Sosial- og helsedepartementet [Ministry of Health and Social Affairs]).

Tranøy, J. and Blomberg, W. (2005) Lobotomy in Norwegian Psychiatry. History of Psychiatry, 16(1): 107-10. 


\section{A personal comment on Einar Kringlen's 2004 article in History of Psychiatry}

Kringlen's article has the title 'A history of Norwegian psychiatry'. I have worked in the mental health services in Norway for many years, both as a clinical psychologist and a researcher, and it seems to me quite ambitious to write a scientific article about such a broad topic: more than 150 years of 'psychiatry' in Norway. Kringlen has managed to collect much material in the article, and some of its themes are informative and interesting. However, I think an article is more likely to be of a high quality if it is limited to themes that the author knows thoroughly.

Therefore I will limit my comment to one passage (p. 278), dealing with a topic I know very well: my own thesis. Kringlen writes:

In a study of Norwegian psychotherapeutic ideologies during the period 1970-2000, Hjort (2001) observed that psychodynamic ideas were dominant among psychiatrists from the 1970 s to the mid-90s. Clinical psychologists were more influenced by behaviour therapy and cognitive theory from the end of the 1970s.

I think that Kringlen does not use my findings properly here. In 1996 I did a survey in which 1100 psychologists (not only clinical) and psychiatrists answered the questions: 'When you started working as a therapist, how much was your work influenced by the following traditions/orientations?' And: 'How much have you been influenced by the following therapy traditions through the different phases of your career?' (The respondents could choose among eight common therapy traditions, which they evaluated on Likert scales.) From the 1100 respondents, I obtained extensive information about how therapeutic ideas in Norway developed and changed during the period from 1950 to 1996 (not only from 1970, since some respondents were quite old! But of course the material was more solid from the 1970s). I also collected information about the differences in ideologies between psychiatrists and psychologists. I published the results in 2000 (not 2001), and it is the largest Norwegian sample of psychologists and psychiatrists that has been asked these questions.

The findings were that both psychiatrists' and psychologists' dominant therapeutic orientation from about 1950 to 1996 was psychodynamic, and this is true for psychiatrists much more than for psychologists. There are many historical theories on the dominance of the psychodynamic tradition. Here, I will focus on why the two professions have differed so much in their adherence to this tradition. Reasons may be that psychiatrists did not have the chance to learn about a variety of therapeutic orientations, whether in their general education or in their specialization, and that they could not become specialists without having a supervisor certified as a psychoanalyst. On the other hand, 
from the early 1970s psychologists in Norway had access to many therapeutic orientations and had more freedom in their choice of supervision. What motivated the two professions seems primarily to have been the need to make a career in becoming specialists, more than seeking knowledge about the best treatment for their patients. I mentioned this hypothesis in my thesis, and I think Kringlen's article would have been more interesting if it had presented more hypotheses and explanations instead of just referring to data (in a rather sloppy way).

The beginning of the 1970s was a time of change in the therapeutic field, and several psychologists (and also some psychiatrists) became interested in more socially-oriented 'inter-psychic' therapy, not only 'intra-psychic'. Family/ systemic therapy therefore became popular. As I show in my thesis, this tradition has continued to be an important therapy orientation in Norway, more influential on the whole than behaviour and cognitive therapy in the mental health services, at least until the mid-1990s. Why does Kringlen not report this? (I know he is more interested in behavioural and cognitive than family/systemic therapy, but ...)

Kringlen also writes (p. 278):

short-term psychodynamic therapies have been more popular among both psychiatrists and psychologists throughout the last decade, often mixed with elements of cognitive therapy.

He does not give any references or explanations for this viewpoint and he does not say what this 'more' is in relation to. I also have impressions of this 'popular' trend in some groups of psychiatrists and psychologists but, as far as I know, there has not been any representative survey study on this.

Data can be used in many ways, and my intention has been to underline that it requires space to present and interpret data in an accurate and interesting way. When I read Kringlen's summary of my laboriously collected data, I thought that perhaps it would have been better if he had not used them.

HALDIS HJORT

Sintef Health Research

PO Box 124, Blindern, Oslo, Norway

Email: haldis.hjort@sintef.no

\section{References}

Hjort, Haldis (2000) Ideer $i$ norsk psykoterapi 1970-2000 [Ideas in Norwegian psychotherapy 1970-2000] (Oslo: University of Oslo).

Kringlen, E. (2004) A history of Norwegian psychiatry. History of Psychiatry, 15(3), 259-83. 


\section{History of Norwegian psychiatry: response to comments}

My article on Norwegian psychiatry in History of Psychiatry (Kringlen, 2004) has raised some objections. In such a brief synopsis, where I focused attention particularly on the last two hundred years, some aspects of Norwegian psychiatry's development could only be touched on or had to be left out. Some of my anti-psychiatric opponents have made useful additions to my paper; however, they often overstate their cases, and also apparently tend to condemn historical developments with the wisdom of hindsight.

In their paper 'Lobotomy in Norwegian psychiatry' Joar Tranøy and Wenche Blomberg (2005) convey the impression that I have hidden the Norwegian lobotomy story, stating that 'Kringlen ... totally neglects the role of Norway's leading post-war psychiatrist in the development of lobotomy/psychosurgery'. Strong words. Let me remind the readers what I wrote (p. 267):

Gaustad Asylum introduced lobotomy in 1941, but most of the 2500 brain-operations were carried out in the post-war years at different psychiatric hospitals. The mortality was usually 1-5\%. At Gaustad Asylum the mortality rate was extreme[ly high] during the first period (1943-48) when nine of 28 patients died after the operation.

Thus I did not neglect the sad history of lobotomy, nor did I avoid mentioning that Ødegarrd introduced lobotomy in Norway or ignore the high death rate at Gaustad hospital where Ødegård was director and thus responsible for patient treatment.

Tranøy and Blomberg seem to think that the initial high mortality rate in Norway was due to surgeons who were not trained in neurosurgery. In general the lobotomy death rate was not particularly high in Norway. Gaustad hospital was a special case, probably because the operations were carried out by Dr Arne Torkildsen who was in fact trained as a neurosurgeon but, according to my information, was obviously rather careless in his treatment of lobotomy patients.

In his paper "Development of "psychiatry" and the mental health services in Norway', Arnulf Kolstad (2005), unlike Blomberg and Tranøy, brings few new facts or ideas into the discussion. In his well-known hair-splitting debate technique, he is on the lookout for sentences that contradict each other. According to Kolstad, I have not defined 'psychiatry' adequately, yet he himself offers no definition. It should be obvious that I tried, possibly with varying success, to describe the patients, the institutions, the treatment ideology, the empirical research and the leading actors in the field of psychiatry.

Kolstad does not accept that Norwegian psychiatry was hospital-based 
before and after World War II, although it is a matter of record that both private practice and outpatient clinics were rare before the 1950-60s. Crowded asylums led to private care for many patients from 1880 until modern times. After hospitalization, these patients were boarded at farms or placed in 'colonies' connected to the asylums. Few were sent directly into private care - which often happened before the asylums were built. Therefore it is correct to characterize this period in Norwegian psychiatry as hospitalbased. Kolstad also finds it remarkable that I can point out that research activity in the 1930s was limited, but that some valuable pieces of work were published. He should know that quantity is not the same as quality. Kolstad refers to Johan Scharffenberg as 'Professor'. He was head of an institution, but never a professor. Kolstad also criticizes the lack of well-known women in my review, but he does not himself mention a single one. My article did not cover child psychiatry, therefore women such as Nic Hoel (Waal) and others were excluded. Kolstad's petty criticism also takes issue with my remark: 'During the last decades we have also witnessed an increasing frequency of common depression, alcohol and substance abuse, anti-social behaviour and suicide in the younger generation.' (p. 279). Of course I am aware of the fact that suicide in the young (as in all age groups) has declined during the 1990s, but since the 1970s we have observed an increase.

Haldis Hjort (2005) is offended by my short account of her research findings. We would all love to be more fully cited when mentioned in the literature. Hjort studied psychotherapeutic ideologies during the period 1950-2000 by mailing out questionnaires to Norwegian psychologists and psychiatrists. She exaggerates the importance of her large sample. Her sample of 1100 replies from approximately 4000 Norwegian psychologists and psychiatrists is not necessarily representative, nor do we know the validity of answers provided. As we all know, many of us fill out such questionnaires in a haphazard and often conventional manner, particularly if the questions are in any way problematic.

\author{
EINAR KRINGLEN \\ Psykiatrisk institutt, University of Oslo \\ Vinderen, Box 85, 0319 Oslo, Norway \\ Email: einar.kringlen@psykiatri.uio.no
}

\title{
References
}

Hjort, H. (2005) A personal comment on Einar Kringlen's 2004 article in History of Psychiatry [Letter to the editor]. History of Psychiatry, 16(2), 253-4.

Kolstad, A. (2005) Development of 'psychiatry' and the mental health services in Norway [Letter to the Editor]. History of Psychiatry, 16(2), 247-52.

Kringlen, E. (2004) A history of Norwegian psychiatry. History of Psychiatry, 15 (3), 259-83.

Tranøy, J. and Blomberg, W. (2005) Lobotomy in Norwegian psychiatry. History of Psychiatry, $16(1), 107-10$. 